\section{JTI}

JOURNAL OF

TRAUMA AND INJURY

Received: March 16, 2021

Accepted: May 11, 2021

\section{Correspondence to}

Kun Hwang, M.D., Ph.D.

Department of Plastic Surgery, Inha University College of Medicine, 27 Inhang-ro,

Jung-gu, Incheon 22332, Korea

Tel: +82-32-890-3514

Fax: +82-32-890-2918

E-mail: jokerhg@inha.ac.kr

ORCID: https://orcid.org/0000-0002-

1994-2538

\title{
Trauma Surgery and War: A Historical Perspective
}

\author{
Kun Hwang, M.D., Ph.D. \\ Department of Plastic Surgery, Inha University College of Medicine, Incheon, Korea
}

The aim of this review is to introduce the progress in trauma surgery made during war. In the 16th century, Paré reintroduced ligature of arteries, which had been introduced by Celsus and Galen, instead of cauterization during amputation. Larrey, a surgeon in Napoleon's military, adapted the "flying artillery" to serve as "flying ambulances" for rapid transport of the wounded. He established rules for the triage of war casualties, treating wounded soldiers according to the seriousness of their injuries and the urgency of medical care. To treat fractures and tuberculosis, Thomas created the "Thomas splint", which was used to stabilize fractured femurs and prevent infection; in World War I (WWI), use of this splint reduced the mortality of compound femur fractures from $87 \%$ to less than $8 \%$. During WWI, Cushing systematized the treatment of head injuries, reducing mortality among head injury patients. Gillies repaired facial injuries, and his experiences became the basis of craniofacial and aesthetic surgery. In WWII, McIndoe discovered that immersion in saline promoted burn healing and improved survival rates, and thus began saline baths and early grafting instead of using tannic acid. A high mortality rate in patients with acute renal failure was noted in WWII and the Korean War. In the Korean War, Teschan used the Kolff-Brigham dialyzer. The first use of medevac with helicopters was the evacuation of three British pilot combat casualties by the US Army in Burma during WWII. As a lotus blooms in the mud, military surgeons have contributed to trauma surgery during wartime.

Keywords: Armed conflicts; Wounds and injuries; Military medicine; History of medicine

\section{INTRODUCTION}

Dante's Inferno is the first part of his three-part epic poem, the Divine Comedy, written in the 14th century. Virgil (Publius Vergilius Maro, 70-15 BC) a poet, guides Dante's journey through the nine circles of Hell (Fig. 1). Dante Alighieri (1265-1321) passes through the gate of Hell, which has an inscription ending with the famous phrase (http://creativecommons.org/licenses/by-nc/4.0/) which permits unrestricted noncommercial use, distribution, and reproduction in any medium, provided the original work is properly cited. 


\section{JTI}

"Abandon all hope, ye who enter here". In modern days, humans experience the "inferno" on the battlefield.

As Virgil guided Dante, I would like to introduce the progress of trauma surgery that has been achieved during war and to present famous trauma surgeons who contributed to modern trauma surgery through their experiences in war.

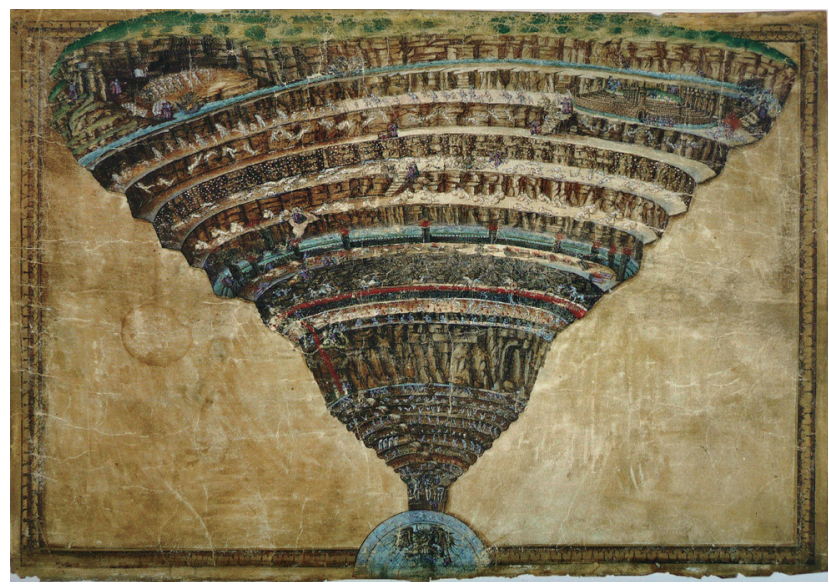

Fig. 1. "Map of Hell" by Botticelli. Available from: https://upload.wikimedia.org/wikipedia/commons/3/3e/Sandro_Botticelli___La_Carte_de_ 1\%27Enfer.jpg.

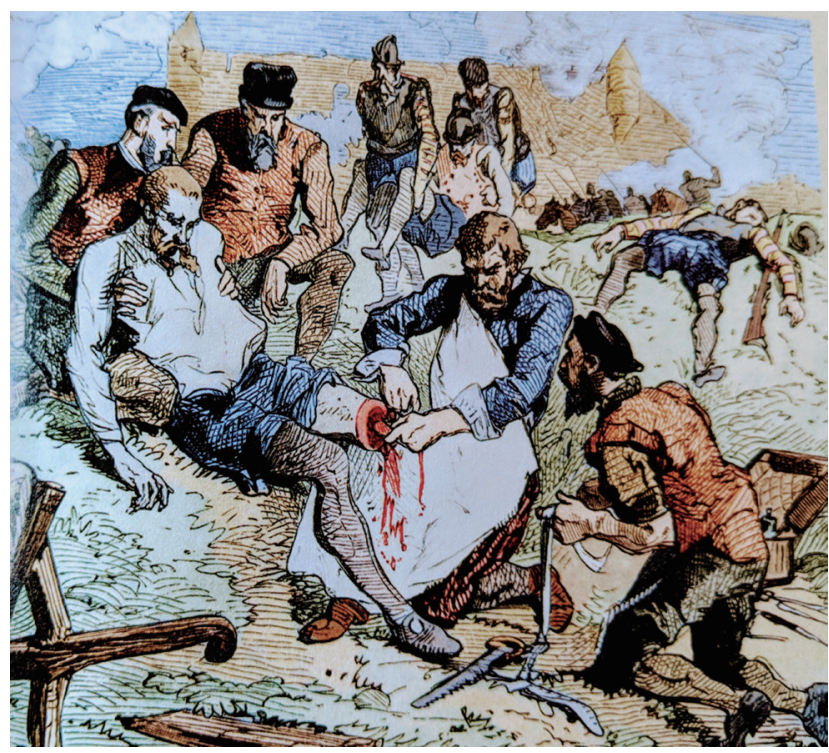

Fig. 2. Paré performing amputation on the battlefield. Available from: https://antiquatedantidotes.blog/2018/10/12/ambroise-pare-i-dressedhim-god-cured-him/.

\section{MAIN BODY}

\section{Pioneering battlefield wound treatment}

Ambroise Paré (1510-1590), a French surgeon, is considered a pioneer in the treatment of battlefield wounds (Fig. 2). He published a book entitled The Method of Curing Wounds Caused by Arquebus and Firearms (1545). He reintroduced ligature of arteries, which had been introduced by Celsus and Galen, instead of cauterization during amputation. During Parés era, the usual method of sealing wounds by searing them with a red-hot iron often failed to arrest the bleeding, which caused patients to die of shock. As a ligature technique, he designed the Bec de Corbeau ("crow's beak"), a predecessor to modern hemostats. He described the technique of using ligatures to prevent hemorrhaging during amputation in his Treatise on Surgery (1564) [1].

\section{Prototype of ambulance and triage}

Dominique Jean Larrey (1766-1842) is considered to be the first modern military surgeon. He was a surgeon in Napoleon's military and an important innovator in battlefield medicine and triage. After seeing the speed with which the carriages of the French "flying artillery" maneuvered across the battlefields, Larrey adapted them to serve as "flying ambulances" for the rapid transport of the wounded and manned them with trained crews of drivers, corpsmen, and litter-bearers (Fig. 3). He increased the mobility and improved the organization of field hospitals, the prototype of modern mobile army surgical hospital (MASH) units. He established rules for the triage of war

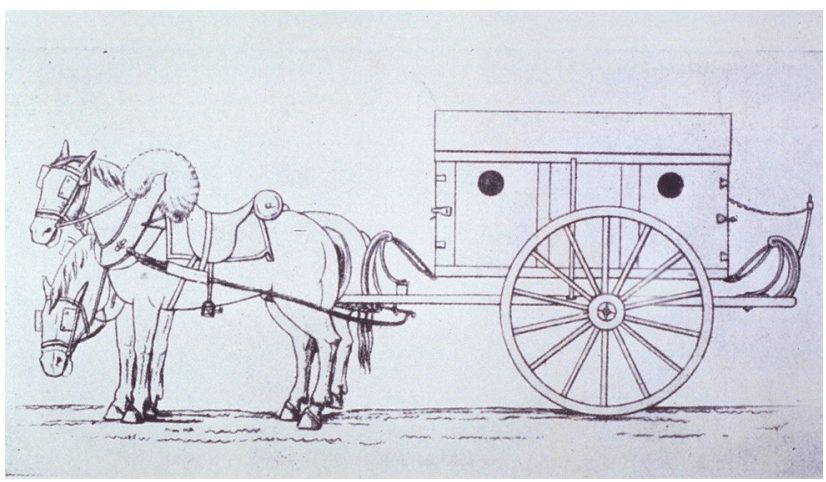

Fig. 3. "Flying ambulance" innovated by Larrey. Available from: https:// commons.wikimedia.org/wiki/File:Larrey\%27s_Flying_Ambulance.jpg. 
casualties, treating the wounded according to the seriousness of their injuries and the urgency of medical care, regardless of their rank or nationality (Fig. 3) [2,3].

\section{Femur fractures and the Thomas splint}

Hugh Owen Thomas (1834-1891), a Welsh surgeon, is considered the father of orthopedic surgery in Britain. In the treatment of fractures and tuberculosis, he advocated rest, which should be "enforced, uninterrupted and prolonged". To achieve this, he created the "Thomas splint", which was used to stabilize fractured femurs and prevent infection (Fig. 4). In his lifetime, however, his work was not appreciated. In World War I, Robert Jones (the nephew of Thomas) applied his splint, the use of which reduced mortality of compound fractures of the femur from $87 \%$ to less than $8 \%$ in the period from 1916 to 1918 [4].

\section{Trench warfare and head/face injuries}

The most famous instance of trench warfare was the

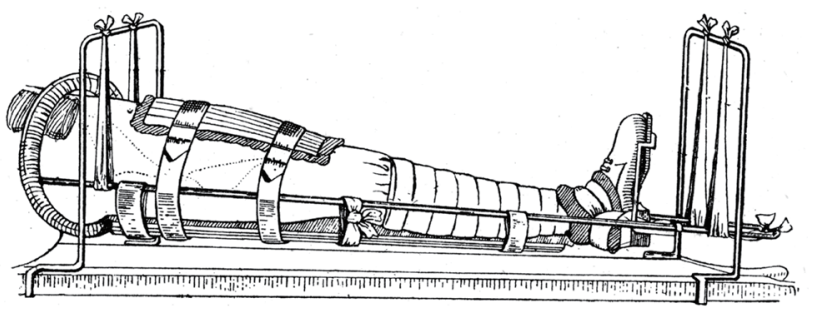

Fig. 4. Diagram of the original Thomas knee splint. From diseases of the hip, knee and ankle joints, with their deformities, treated by a new and efficient method by Thomas (1876).

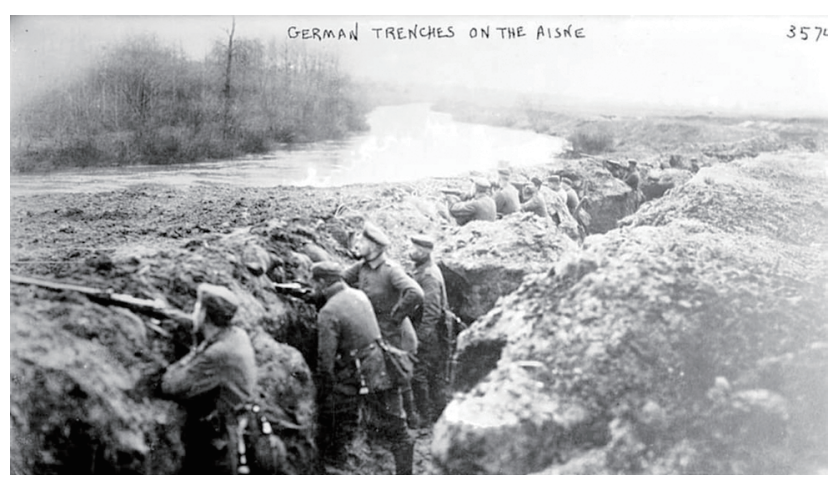

Fig. 5. Casualty in a trench. Available from: https://www.mentalfloss. com/article/58898/wwi-centennial-birth-trench-warfare.
Western Front in World War I (WWI). In this war, the machine gun entered widespread use for the first time. Soldiers stayed in trenches, in which troops were well-protected from the enemy's fire and sheltered from artillery. In the trenches, soldiers could hide their bodies. However, their heads and faces were exposed to the enemy's fire, and therefore head and facial trauma occurred frequently (Fig. 5) [5].

Harvey Cushing (1869-1939) was a major contributor to the treatment of head injuries. When he was at a French military hospital in 1917, he extracted fragments of metallic missile shrapnel that were lodged deeply within the brain using electromagnets. During 4 months in 1917, he treated 219 wounded soldiers, including 133 gunshot wounds that penetrated the dura mater. He developed de-



Fig. 6. Gillies' reconstruction of gunshot deformities. Available from: https://www.history.com/news/world-war-i-plastic-surgery-innovations-gillies. 


\section{JTI}

bridement using negative pressure, and dura repair using the fascia lata. He also systematized the treatment of head injuries, reducing mortality among head injury patients.

When WWI began, Harold Gillies (1882-1960), a plastic surgeon, joined the Royal Army Medical Corps. In France, he met a dentist, Charles Valadier (1873-1931), and learned the basics of repairing jaw injuries, including how to perform bone grafting. After his return to England, he worked at the Queen's Hospital, which was

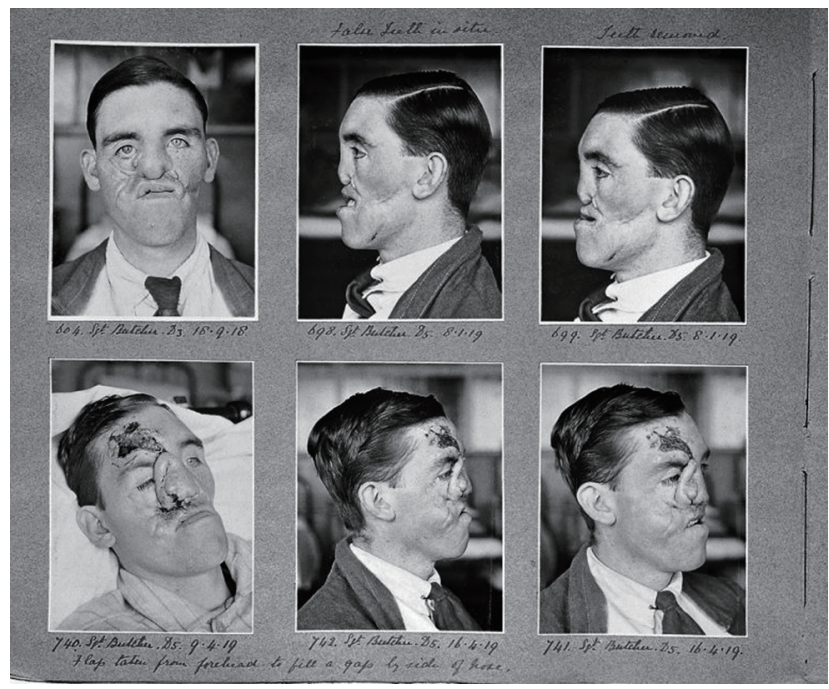

Fig. 7. Mclndoe's reconstruction of facial burn. Available from: https:// canadianmilitaryhistory.ca/what-is-a-guinea-pig-plastic-surgery-andthe-second-world-war/.

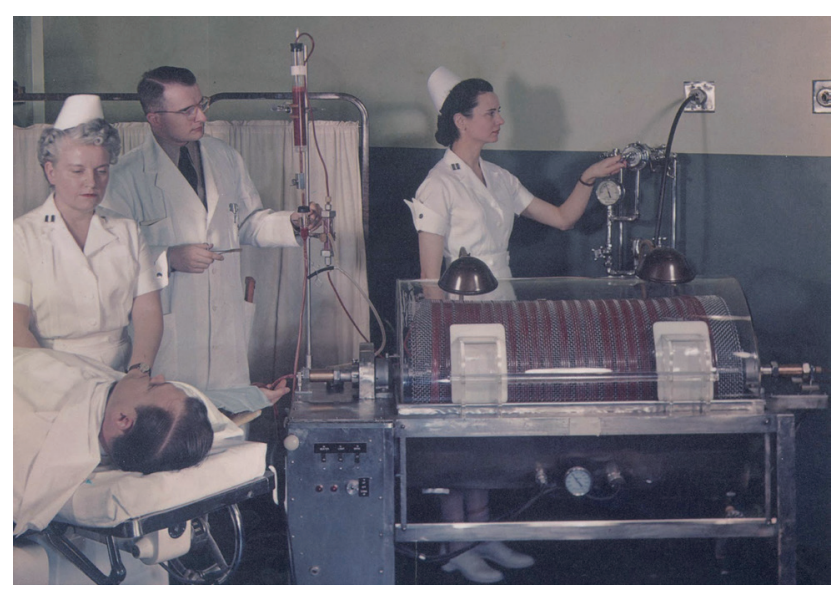

Fig. 8. Brochure illustration of the Kolff-Brigham dialyzer made by the Edward Olson Company. Available from: http://historyofnephrology. blogspot.com/2011/01/korean-war-1950-3.html. devoted to facial repairs. He developed several plastic surgery techniques. From 1917 to 1925, he performed more than 11,000 operations in 5,000 soldiers with facial injuries (Fig. 6). His experiences with head and facial injuries became the basis of craniofacial surgery, and his innovations were also applied to congenital craniofacial malformations. Through treating severely injured faces, he accumulated surgical experiences with the face that led to the development of aesthetic surgery [6].



Fig. 9. A helicopter of the US forces during the Korean War. Available from: https://www.defensemedianetwork.com/stories/battlefield-medicine-in-the-korean-war/.

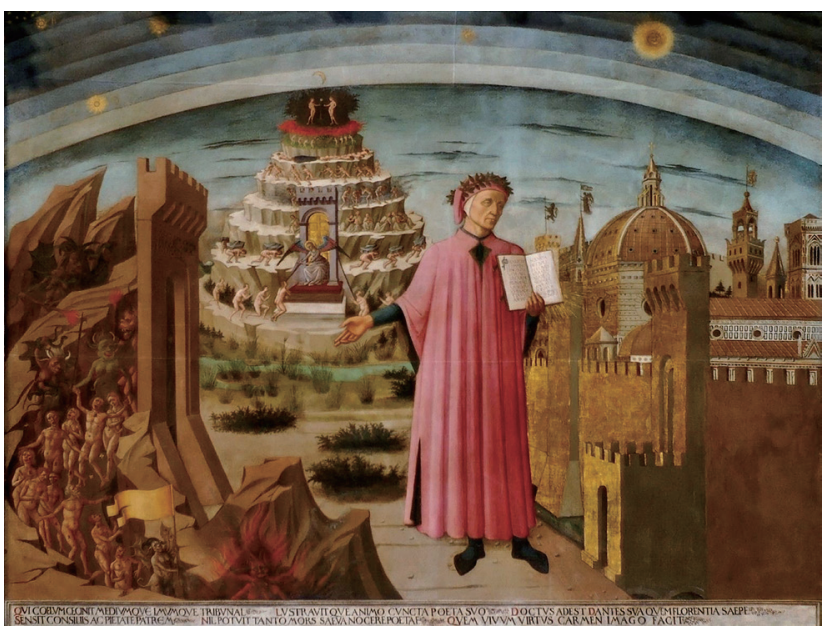

Fig. 10. Portrait of Dante Alighieri in Duomo (Florence Cathedral). Available from: https://commons.wikimedia.org/wiki/File:Dante_Domenico_ di_Michelino_Duomo_Florence.jpg. 


\section{Severe burns from bombers}

In World War II (WWII, 1939-1945), the survival rates from combat wounds increased due to the development of blood transfusion, endotracheal intubation, and rapid evacuation by aircraft. However, severe burn cases became increasingly widespread due to massive air strikes from bombers. Therefore, burn care significantly advanced during WWII. Following the outbreak of WWII, Archibald McIndoe (1900-1960) moved to the newly built Queen's Hospital and treated deep burn injuries and serious facial deformities, such as the loss of eyelids. At that time, the standard treatment for burns was coagulation with tannic acid, which is very painful. He observed different healing rates in extensively burned pilots who had come down on land and in the sea. Based on these observations, he discovered that immersion in saline promoted healing and improved survival rates, and thus began saline baths and early grafting instead of using tannic acid. He recognized the importance of rehabilitation and social reintegration back into normal life (Fig. 7). Over $80 \%$ of his aircrew patients returned to their duty [6].

\section{Treatment of acute renal failure in military casualties}

The high mortality rate in military casualties who developed acute renal failure (ARF) was noted in both WWII (1939-1945) and in the Korean War (1950-1953). During these wars, it was reported that $80-90 \%$ of soldiers with ARF died. At the 11th Evacuation Hospital of the 8th Army, a renal center was established. Paul Teschan (19422004) arrived in 1952 with artificial kidney technology, and oliguric patients-despite having a reasonable blood pressure-were treated by this specialist team. In Korea, this team used the Kolff-Brigham dialyzer, which was modified version of Kolff's rotating drum machine (Fig. 8) [7].

\section{Aircraft as ambulances}

As with many emergency medical service innovations, treating patients in flight originated in the military. Air evacuation was experimented with during WWI. The first true Air Ambulance flight was from the battlefield to the hospital by a plane of the French Air Service. The mortality rate of the injured was reduced from $60 \%$ to just under $10 \%$ if they were evacuated by air.
The first use of medevac with helicopters was the evacuation of three British pilot combat casualties by the US Army in Burma during WWII. The first dedicated use of helicopters by US forces occurred during the Korean War (Fig. 9). By 1969, in Vietnam, specially trained medical corpsmen and helicopter air ambulances were used and they transported casualties within the "golden hour". The US military also employed UH-60 Black Hawk helicopters to provide air ambulance services during the Iraq War to military personnel and civilians [8].

\section{CONCLUSION}

As Virgil guided Dante, I have introduced the progress of trauma surgery during war (Fig. 10). As a lotus blooms in the mud, military surgeons have contributed to trauma surgery during wartime. Even in the midst of war, which is like passing through the gates of Hell, we should not abandon hope, because we are trauma surgeons.

\section{CONFLICTS OF INTEREST}

No potential conflict of interest relevant to this article was reported.

\section{INFORMED CONSENT}

This type of study does not require informed consent.

\section{ACKNOWLEDGEMENTS}

This work was supported by a grant from National Research Foundation of Korea (NRF-2020R1I1A2054761).

\section{REFERENCES}

1. Hwang K. Tracing the use of cautery in the modern surgery. J Craniofac Surg 2018;29:12-3.

2. Dible JH. Napoleon's surgeon. London:William Heinemann 
Medical Books Ltd;1970.

3. Richardson RG. Larrey: surgeon to Napoleon's imperial guard. London:John Murray;1974.

4. Robinson PM, O’Meara MJ. The thomas splint: its origins and use in trauma. J Bone Joint Surg Br 2009;91:540-4.

5. Hwang K. Trench coats, cushing, and gillies. Arch Craniofac Surg 2018;19:83-4.

6. Hwang K. Portraits of two innovative plastic surgeons in the
National Portrait Gallery. Plast Aesthet Res 2017;4:15-7.

7. History of Nephrology. The Korean War 1950-3: acute dialysis finds its place [Internet]. Edinburgh: History of Nephrology 2011 [cited 2021 Mar 16]. Available from: http:// historyofnephrology.blogspot.kr/2011/01/korean-war-1950-3. html\#!/2011/01/korean-war-1950-3.html.

8. Lam D. Wings of life and hope: a history of aeromedical evacuation. Probl Crit Care 1990;4:477-94. 